WellBeing International

WBI Studies Repository

1985

\title{
Anthropomorphism is Not a Four-Letter Word
}

Randall Lockwood

The Humane Society of the United States

Follow this and additional works at: https://www.wellbeingintlstudiesrepository.org/acwp_arte

Part of the Animal Experimentation and Research Commons, Animal Studies Commons, and the Other Psychiatry and Psychology Commons

\section{Recommended Citation}

Lockwood, R. (1985). Anthropomorphism is not a four-letter word. In M.W. Fox \& L.D. Mickley (Eds.), Advances in animal welfare science 1985/86 (pp. 185-199). Washington, DC: The Humane Society of the United States.

This material is brought to you for free and open access by WellBeing International. It has been accepted for inclusion by an authorized administrator of the WBI Studies Repository. For more information, please contact wbisr-info@wellbeingintl.org.

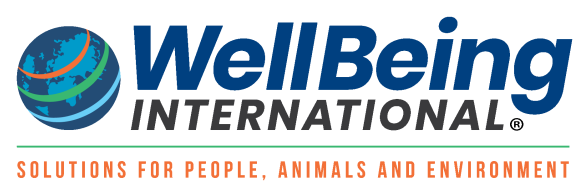




\section{ANTHROPOMORPHISM IS NOT A FOUR-LETTER WORD*}

\section{Randall Lockwood}

The Humane Society of the United States

2100 L Street, NW

Washington, D.C. 20037

In recent years animal experimentation in American psychology has been subjected to harsh criticism from inside and outside the discipline (Bannister 1981; Giannelli, this volume; Griffin 1976, 1984; MacDonald and Dawkins 1981; Rollin 1981). The critics have warned of a loss of both an ethical framework and a creative spark in contemporary psychology. It is no secret that much of what passes for good science in psychology is trivial, boring, repetitive, and inhumane. I think that many of the factors that stifle creativity in this field are the same ones that lead researchers to conduct studies that are ethically impoverished. Conversely, I believe that an empathic and humane viewpoint often encourages scientists to ask valid scientific questions that are fresh, challenging, and beneficial to human and non-human animals alike.

How did psychology, particularly American comparative psychology, get into this sterile and often cruel rut? I would like to examine that question by briefly reviewing the history of the field and my own experiences as a student in this area.

When I first entered the world of the scientific study of animal behavior almost twenty years ago, I was given the distinct impression that it was time to put away my teddy bears and memories of Disney films and acquire the cold, hard, "objective" eye of the scientist. My textbooks were quite clear about the dangers of viewing animals in any other way:

*This paper is based on invited presentations at the Conference on the Perception of Animals in American Culture, National Zoological Park, Washington, D.C., November 1983 and the American Psychological Association, Toronto, Canada, August 1984. 
We cannot see into the animal's mind any more than we can see into that of any of our fellow humans, but that doesn't prevent us in both cases from thinking that we can. The animal may seem sad or happy, but we cannot infer that this is the case from the way that we ourselves might feel in the same situation. To do so is to indulge in anthropomorphism - seeing man's shape in all things - and this is the cardinal crime (emphasis mine) for the animal observer (Broadhurst 1964, p. 12).

Another text from this same period warns:

Sometimes we fall into the dangerous pit of anthropomorphism (emphasis mine) (which literally means "formed like a man") or the tendency to think of animals as if they were human (Breland and Breland 1966, p. 3).

Most animal scientists are directly or indirectly instructed to avoid any hint of anthropomorphism, yet it is an approach that is invariably applied by scientists and lay people alike. Science may have gained some objectivity in discarding this common view of animals, but it has gone overboard in its rejection of the concept of the continuity of human and animal experiences. I hope to outline how an anthropomorphic perspective can be applied in ways that are a service to science and the animals themselves.

Early accounts of animal behavior were both anthropomorphic and anthropocentric. Animals were seen as existing only for man's benefit, or to provide him with some moral lessons about the power and potential wrath of God or gods. Prior to the nineteenth century most natural histories were anecdotal and largely erroneous. The deficiencies made it difficult to equate the study of animal behavior to the quantitative sciences such as physics, chemistry, and astronomy, which were experiencing dramatic growth and vigor during this period.

Charles Darwin made extensive but careful use of anecdotal reports in many of his greatest works. His descriptions of behavior were also highly anthropomorphic. He wrote, for example:

Dogs exhibit their affection by desiring to rub against their masters... I have also seen dogs licking cats with whom they were friends. This habit probably originated in the females' carefully licking their puppies - the dearest object of their love-for the sake of cleansing them (Darwin 1872, p. 118).

Darwin's anthropomorphism is partly based on literary style. We must remember that he was a best-selling author, with the first edition of Origin of Species selling out in a single afternoon. But Darwin's language also reflected his firm belief in the continuity of life, including a continuity of mental experiences.

A major concern during the 1870 s and 1880 s was the evolution of the human mind. Thus there was a comparable interest in the mental abilities of animals. Scientific journals of the era were flooded with 
letters reporting striking observations on the mental abilities of animals (Boakes 1984).

Many of Darwin's later contemporaries were eager to join the ranks of the "legitimate" physical scientists and were critical of the anthropomorphic approach. Darwin's initial entry into respectable scientific circles had been based primarily on his rather dry geological writings. His most anthropomorphic book, Expression of the Emotions in Man and Animals (1872), was largely ignored by the scientific community for many years.

Prior to his death in 1882, Darwin chose George Romanes as his intellectual successor and entrusted to him the task of compiling his vast correspondence relating to the mental abilities of animals. Sensing the swing to the methods of the physical sciences, Romanes expressed fears that his book on this topic, Animal Intelligence (1882), would be considered small improvement on the works of the "anecdote mongers." His predictions proved correct. His work has been unjustifiably ignored including his insightful notion of "ejection," the idea that we can infer the mental state of animals having some similarities to ourselves by reflecting on our own mental states under similar conditions.

In 1894, one of Romanes' students, C. Lloyd Morgan, released his Introduction to Comparative Psychology. The book echoed many of Romanes' ideas and stressed the importance of both subjective and objective approaches to understanding the mentality of animals. However, Morgan's book is most remembered for a simple statement on method which, taken out of context, became the guiding light for American biologists and psychologists. This idea, now immortalized as "Morgan's Canon," was brief and deceptively simple. He wrote:

In no case may we interpret an action as the outcome of the exercise of higher psychical faculty if it can be interpreted as the outcome of the exercise of one that stands lower in the psychological scale.

Over the years this has generally been interpreted to mean that one should not refer to "intelligence," when the concept of "instinct" will suffice and that one should examine clearly identifiable reflexes and simple behaviors, rather than search for an understanding of animal or human "mind."

Like many statements in science that have achieved the status of dogma, Morgan's Canon had the effect of both freeing psychology from some of its pseudoscientific trappings while, at the same time, slamming the door on some of the most interesting questions possible.

Most of the major figures in the study of animal behavior from 1890 to the 1950 s embraced Morgan's idea. Pavlov (1927) wrote that animals should be studied as "physiological facts, without any need to resort to fantastic speculations as to the existence of any possible subjective states... which may be conjectured as an analogy with ourselves." 
In America, John B. Watson set the tone for animal research for the next forty years when he proclaimed the official position of Behaviorism. He wrote that "States of Consciousness', like the so-called phenomena of spiritualism, are not objectively verifiable and for that reason can never become data for science" (Watson 1924).

As some have described it, this is the point where psychology, having already lost its soul, proceeded to lose its mind. Given the choice between accepting the possibility of mind and emotion in animals and man, and trying to build a theoretical framework around that, or denying the importance of subjective experiences, most psychologists chose the latter. A direct outgrowth of this approach was the proliferation of mechanical models of animal and human behavior that have been demeaning to both (Bannister 1984).

It is unclear exactly what we are being protected from by avoiding anthropomorphism. For the last 100 years the implication has always been that anthropomorphism is bad science, but what does that mean? A primary purpose of scientific method is to enable us to make valid predictions about the world. The better our science, the better the forecasts we are able to make. Physics, astronomy, and chemistry have been revered for their ability to make nearly infallible predictions. Biology has lacked this level of precision, but is still strongly predictive. Psychology has generally failed this test quite badly except for predictions made under conditions where the behavioral options are severely limited. It is for this reason that it is often not even considered a "science," even in its position within academic hierarchies.

If anthropomophism generates bad science, or science that is worse than that offered by alternative behavioristic approaches, then that should mean that the hypotheses we generate based on assuming things like animal emotion, intelligence, feeling, intention and so on, will be very inaccurate. But modern interpretations of Morgan's Canon, Pavlov's pronouncements and the position of Behaviorism tell us not to even bother asking the questions! To many animal scientists, the study of animal consciousness, animal emotion, or animal suffering is a contradiction in terms, like a scientific study of the soul. I find it hard to accept as "scientific" any philosophy that automatically excludes entire areas of inquiry.

In an attempt to avoid any taint of anthropomorphism, the research of Pavlov, Loeb, Watson, Skinner, and their contemporary ideological descendants often takes the form of precisely measured studies of trivial events. There has been, and continues to be, a fascination with studying areas of animal behavior that lend themselves to precise, objective, and often remote measurement. This is not so much because these events are intrinsically interesting or even theoretically important, but often simply because their measurement is possible! The result has been a body 
of "research" that represents the expensive measurement of the irrelevant and the painful elaboration of the obvious.

In the 1940s and 1950s, while American psychologists followed a largely Behaviorist tradition, ethologists in Europe were rediscovering many of the Darwinian traditions. Tinbergen's methods were the result of a desire to understand the entire pattern of an animal's adaptations to its natural environment, as well as the desire to study mechanisms of behavior without damaging the animal in any way. He described his procedures as "physiology without breaking the skin" (Tinbergen 1958). Lorenz, Tinbergen, von Frisch, and others performed naturalistic observations and natural experiments, all in accordance with accepted scientific method. However, they felt free to discuss their results, as Darwin had, with reference to animal minds, intentions, and feelings.

As with Darwin, part of this was for literary effect. Like Darwin's Origin of Species, Lorenz's books King Solomon's Ring and On Aggression became best-sellers. But the anthropomorphic tone of these books reflected a very different philosophical viewpoint from that found in the writings of most American comparative psychologists. It was one that had been neglected for some time in this country. Lorenz made it clear that his anthropomorphism was not to be confused with softheaded sentimentality:

Believe me, I am not mistakenly assigning human properties to animals; on the contrary, I am showing you what an enormous inheritance remains in man to this day (1952 p. 152).

Ironically, one outgrowth of ethology's popularity in the 1960 s and 1970s was the proliferation of "zoomorphism," the widespread application of concepts of animal behavior to human motivation and behavior. While the intellectual stock of this approach has declined dramatically, it has been followed by the more systematic application of principles of inclusive fitness to human and nonhuman behavior by contemporary sociobiologists who are often comfortable with freely interchanging terms drawn from studies of both human and animal behavior. Despite this renewed interest in the continuity of human and nonhuman experiences, the fear of anthropomorphic interpretation has still kept the study of the mental and emotional experiences in animals outside the reach of most mainstream psychologists and biologists.

The continuing aversion to anthropomorphism is partly due to confusion about the actual meaning of the term. Few students of behavior take the time to consider what it is they are supposed to be avoiding. Thus they tend to avoid any thinking or writing that seems to touch on parallels between animal and human mental events. At this point it is important to clarify some of the different meanings that the term "anthropomorphism" can have. In this way we might understand the almost irrational ends to which scientists have gone to avoid it. 
Let's examine these safeguards in detail. For the entire process of projective anthropomorphism to be of scientific value, there must be some analog of the experience of others in our own repertoire. If I enjoy a particular book about natural history then I can predict with some certainty that a friend who has exhibited a parallel interest will also appreciate the book. However, it would probably be erroneous for me as a nonparent to approach a mother who has just buried a child and say "I know how you must feel." I have known grief, but I doubt that my experiences have given me a pattern of responses and emotions that are fully analogous to what the parent is experiencing. Thus I cannot really predict how she wil respond to being left alone, comforted, etc. A similar problem arises when trying to fit our behavioral framework on the experiences of animals. Niko Tinbergen recognized his inability to relate to the experience of incubation on the part of a herring gull. He described the event as:

...monotonous, at least for the observer who, missing any incubation instinct in himself, has some difficulty in understanding the satisfaction which a bird presumably feels when just sitting on eggs (Tinbergen 1953, p. 134).

How are we to judge when there is the potential for some analogy between our own mental experiences and those of another species? One potential source of support for such parallels is the study of the physiological substrates of these experiences. As we gain an increasing understanding of the anatomical, physiological, and pharmacological events that underlie the experience of emotional states in animals and man, we are constantly forced to realize the extent of close parallels in a wide variety of animals. The neurotransmitters and other biological elements implicated in such human experiences as pain, depression, stress, and anxiety are remarkably widespread throughout the animal kingdom. Indeed many critics of contemporary animal psychology (e.g., Giannelli,this volume; Singer 1975) have alluded to the central ethical fallacy of much of this research. Simply stated: if animals used to model the human experience of pain, fear, depression, anxiety, helplessness, and other maladaptive states do not experience these conditions themselves, then their use as models is scientifically unjustifiable. If they do experience such states, their use is morally and ethically unjustifiable.

A second methodological safeguard we can use in applying an anthropomorphic perspective is to pay attention to the context in which a behavior occurs. When dealing with other people we find that our predictions tend to fail when we do not know the events that preceded the behavior that we are trying to understand. Such errors are most likely to occur in dealing with people from different cultural backgrounds. Similarly, anthropomorphism fails when we are insensitive to the biology, ecology, and evolutionary history of the animal, as well as its 
individual life history (concerns that are usually of no interest to the majority of American psychologists).

When my colleagues and I released a pack of captive-raised wolves into the Alaska wilderness, many people suggested that the animals would immediately vanish, based on their own predicted response to release from confinement. In fact, the wolves returned each night for nearly a week to sleep in the temporary cage in which they had been allowed to recover from their journey. Similarly, nearly all of the Arctic foxes released from a fur farm by protesters returned to their small cages within a few days (MacDonald and Dawkins 1981). Neither of these events is surprising when one considers the life history of the animals and the fact that confinement, for these animals, had a life-long association with food and safety. Obviously neither event should be construed as evidence that captivity is not stressful for either wolves or foxes, only that the initial release from captivity is more stressful than captivity itself for those animals that have never experienced anything else. Dawkins (1980) specifically notes the need to take an animal's past environmental history into consideration when interpreting the results of experiments that involve allowing chickens to select to live in standard battery cages or larger quarters.

To summarize, anthropomorphism must be applied with certain restraint. We must have reason to believe that there is potential for analogous experiences and we must have a good understanding of the animal's ecological, evolutionary, and individual history. Then we are free to use our empathy to make a prediction, which we must then evaluate. If the prediction holds up, I feel that this constitutes scientific evidence for the validity of the initial anthropomorphic assumption. We are then in a position to make increasingly more refined predictions, and from this construct a clearer understanding of what it is like to be some other human or nonhuman animal. This is essentially the process we use on a daily basis in building our friendships and other social relationships. It is a process that is almost universally employed but largely unconsciousness to us. It is precisely these properties that have made such an approach unattractive to most American psychologists. That view seems to be changing.

Recently many of the concepts that entranced Darwin and others of his era, such as animal intelligence and emotion, have returned to scientific prominence (see below). This has been brought about by a number of factors. First, ethology's rapid rise in popularity in the 1960s and 1970s resulted in a considerable infusion of fresh ideas into many American studies in animal behavior. Textbooks no longer speak of the contrast between European ethology and American comparative and physiological psychology, but instead point out the productive exchange of ideas. This has resulted in greater emphasis on studies that make 
reference to the adaptive value of behaviors witnessed in the laboratory and has made possible the serious investigation of the mental capacities of animals.

Secondly, the growth in power and sophistication of both the environmental and humane movements during this same period has produced scientists and non-scientists who are increasingly sensitive to both the biological relevance and the ethical basis of research. This change has not always been a rapid one, since charges of sentimentality and anthropomorphic thinking have frequently been leveled at the more compassionate members of the scientific community. Our society finally seems to be learning that one can separate methodology and ideology. An empathetic scientist, having selected a question he or she finds interesting, can gather data in accordance with the strictest tenets of scientific method.

A third factor has been the growing dissatisfaction with the predictive powers of hard-core Behaviorism in dealing with both higher human functions, such as problem solving, and naturally occuring animal behavior. Despite the claims of practitioners of this form of science, its applications to real-world issues have proven to be very limited.

We have not simply come full circle back to 1872 . Today's scientists do not discuss anger, jealousy, nobility, and joy in all manner of insects, birds, and mammals in the same uncritical fashion as those of the nineteenth century. As Marian Dawkins (1980, p. 1) points out:

Present day studies on the mental experiences of animals are far more rigorous and experimental than they were in the nineteenth century. The lessons of Behaviourism have not been lost. Perhaps the study of mental events in animals has advanced precisely because it had to stand up to the Behaviourists and justify itself in the face of their criticisms.

The late C.W. Hume, founder of the Universities Federation for Animal Welfare, commented that no students of behavior would know what to look for if they did not, consciously or unconsciously, use subjective clues (Hume 1962).Let me briefly review a few of the areas of scientific inquiry that have been helped by an anthropomorphic perspective and a sensitivity to these subjective clues.

\section{Animal Learning}

The study of animal learning has been dramatically enriched by breaking out of the intellectual and ethical impoverishment of standard Behavioristic paradigms. Fresh approaches have been produced by returning to the realization that much of animal behavior is done on purpose and that animals are not only "aware" of the consequences of their actions, but often have expectations of what these consequences might be. As Griffin (1984) notes, "if consciousness is an illusion ... it is a 
remarkably useful one." This view is still a minority opinion. "Methodological behaviorism" (Staddon 1983) remains the standard approach for American psychologists. To the question "are there really such things as beliefs and desires and so on?" this approach answers "Maybe... but who cares?"

Even among learning theorists antagonistic to the concept of animal rights there is recognition of the merits of anthropomorphism as a tool for understanding animal behavior. For example, John Garcia's significant contributions in the study of taste aversion learning in rats seem to have come, at least in part, from a willingness to try to understand the world as viewed by a scavenger that eats garbage and cannot vomit. He notes (Garcia 1981, p. 151):

\begin{abstract}
I always use anthropomorphism and teleology to predict animal behavior because this works better than most learning theories. I could rationalize this heresy by pointing to our common neurosensory systems or to convergent evolutionary forces. But, in truth, I merely put myself in the animal's place. I cannot think in the cryptic jargon of learning theory.
\end{abstract}

\title{
Animal Communication
}

As with animal learning, most studies of animal communication that were done just a few years ago focused on the objective and often tedious description of animal sounds and postures and their context. These signals were viewed as behaviors that were motivated by some basic biological need and responded to in some reflexive way. Recently there has been considerable interest in analyzing animal communication from the standpoint of the message that the animal intends to send, and the behavior that it intends (or perhaps "hopes") to elicit in the recipient. There has also been renewed interest in the extensive parallels across species in certain common signals that are conveyed in common ways. These objective studies have strongly vindicated many of Darwin's writings on animal expression, and have raised questions about even more complex cognitive abilities.

\section{Comparative Psychopathology}

The idea of using animals to model human psychiatric disorders was challenged for years because of the assumption that mental suffering required a "mind," and thus could not be considered to exist in "mindless" animals. It is this resistance to the concept of mental disorders in animals that, I think, forced Harlow and his associates to go to drastic extremes to produce animals that were very clearly abnormal. 
Today, there is continued use of animal models, with greater emphasis on the alleviation of disorders rather than the induction of abnormal states. Still, further intellectual growth of this field has been hampered by the preponderance of researchers who use animal models but who remain unwilling to acknowledge that the mental experiences of their animal subjects parallels the discomfort and distress experienced by the humans that they allegedly mimic. There have been many rat and monkey models of depression, yet most researchers would consider it unnecessarily anthropomorphic to hypothesize that their subjects "feel depressed." Such a consideration could generate many fresh hypotheses about the nature of illness and the ways in which it can be alleviated. Even Harlow eventually recognized that a problem with comparative psychopathology was not its reliance on the concept of animal mind, but on the extent to which the animals could suffer as much as people. In reviewing his life's work he said (Harlow and Mears 1979, p. 218):

Perhaps our greatest, most significant discovery is that human behavior generalizes to monkeys, whether or not monkey behavior generalizes to humans.

\section{The Human/Companion Animal Bond}

We are obviously most likely to be anthropomorphic about the animals that we deal with on a daily basis. It is partly for this reason that the study of the behavior of domestic animals became scientifically acceptable only in the last few decades. The formal scientific study of dogs and cats, our closest companions, has only become fashionable in the last few years (Katcher and Beck 1983).

For years, scientists have rejected farmers, livestock handlers, and pet-owners as a source of valid ethological questions, and have shunned observations of domestic animals in favor of expensive and time-consuming studies of exotic animals whose Umwelts are largely unknown. Once again Darwin was a noteworthy exception. He made extensive observations of his own pets and relied heavily on the reports of livestock breeders and handlers in developing many of his ideas about domestication.

Douglas Spalding, a contemporary of Darwin who later influenced Lorenz and the European ethologists, also lamented the lack of interest in domestic animals shown by animal behaviorists of his era. He noted that "the many extraordinary and exceptional feats of dogs and other animals seem to be constantly falling under the observation of everybody except the few that are interested in these matters" (quoted in Boakes 1984).

The growing appreciation of the mental abilities of domestic animals, and the nature of their emotional bonds to humans and each 
other has made possible the rich and vital field of the study of the human/companion animal bond. Still, far more money is being spent on studying the communicative behavior of exotic species than that of the dog, an animal that has shared our social world for over 12,000 years. I look forward to the time, not far off, when we can recruit pet owners into the ranks of objective observers of animal behavior and tap an enormous resource for understanding the interdependence of animals and man.

\section{Applied Ethology}

Another discipline that has benefitted from the scientific application of anthropomorphic ideas is applied animal behavior. This field seeks to use principles of ethology and comparative psychology to modify animal behavior or adjust environments to produce desirable behaviors. A few years ago the notion that animals in captivity or confinement might suffer from boredom, stress, loneliness, or similar conditions would have been considered sentimental anthropomorphism by veterinarians and "hard" scientists. However, a growing number of investigators find such concepts useful in generating hypotheses about how to improve captive environments.

As an example of this change of approach, consider recent trends in housing for the great apes. Chimps and gorillas in captivity often appear to be sad, bored, and lonely to both lay people and trained animal scientists alike. In the past this view could easily be dismissed as sentimentally anthropomorphic. But it can also be used as a working hypothesis without being hampered by the fact that we cannot directly "know" the animal's mental state. If we hypothesize that the animal is bored, and that this boredom is responsible for the various behavioral abnormalities we see such as listlessness, masturbation, regurgitation and refeeding, then we can also hypothesize that relief of boredom should relieve the symptoms. To evaluate the hypothesis we need only assess the results of enriching the animals' environment with toys, social companions, and other sources of stimulation. Such changes almost invariably result in the same kinds of improvements in animal behavior that we would predict on the basis of introspection into our own responses to captivity (Markowitz 1982).

A similar empathic approach has helped the study of misbehavior in companion animals. Borchelt (1983) has found it useful to regard many of the destructive behaviors shown by dogs to be the consequence of "separation anxiety." By attending to the cues that would exaggerate or reduce this hypothetical state, he has been able to design effective treatment programs. 


\section{Animal Welfare}

It would have been unthinkable not so long ago to propose to conduct scientific studies of animal suffering. Today there is great concern about assessing animals' experiences of pain, and the response of animals to different conditions of care. This change has not simply been the result of increased sensitivity to the lobbying efforts of the humane movement. It is a true reflection of many scientists' realization that these questions, rooted in anthropomorphic projections, are timely, interesting, biologically valid, and morally significant.

In summary, I hope that I have clarified the difference between various forms of anthropomorphism and have illustrated its slowly growing respectability as a scientific tool. There will always be barriers to understanding other beings. It is a disservice to ourselves and to our fellow human and nonhuman creatures to regard any attempt at reaching out as being merely irrational or sentimental. If we make use of an ideology based on empathy and a methodology based on science, we cannot go far wrong. Hume (1962) outlines the costs and benefits quite clearly:

If I assume that animals have subjective feelings of pain, fear, hunger and the like, and if I am mistaken in doing so, no harm will have been done; but if I assume the contrary, when in fact animals do have such feelings, then I open the way to unlimited cruelties... Animals must have the benefit of the doubt, if indeed there be any doubt. 


\section{References}

Bannister, D. 1981. The fallacy of animal experimentation in psychology. In: Sperlinger, D. ed. Animals in Research. New York: John Wiley and Sons.

Borchelt, P. 1983. Separation-elicited behavior problems in dogs. In: Katcher, A.H. and Beck, A.M. eds. New Perspectives on Our Lives with Companion Animals. Philadelphia: University of Pennsylvania Press.

Boakes, R. 1984. From Darwin to Behaviourism. London: Cambridge University Press.

Breland, K. and Breland, M. 1966. Animal Behavior. Toronto: MacMillan.

Broadhurst, P.L. 1963. The Science of Animal Behaviour. Baltimore: Penguin Books.

Dawkins, M.S. 1980. Animal Suffering: The Science of Animal Welfare. New York: Chapman and Hall.

Darwin, C. 1872. The Expression of the Emotions in Man and Animals. (1963 reprint). Chicago: University of Chicago Press.

Garcia, J. 1981. Tilting at the paper mills of academe. American Psychologist. 36(2):149-58.

Griffin, D.R. 1976 The Question of Animal Awareness. New York: The Rockefeller University Press.

Griffin, D.R. 1984. Animal Thinking. Cambridge, MA: Harvard University Press.

Harlow, H.F. and Mears, C. 1979. The Human Model: Primate Perspectives. New York: John Wiley and Sons.

Hume, C.W. 1962. Man and Beast. Herts, U.K; The Universities Federation for Animal Welfare.

Katcher, A.H. and Beck, A.M. eds. 1983. New Perspectives on Our Lives with Companion Animals. Philadelphia: University of Pennsylvania Press.

Lorenz, K.Z. 1952. King Solomon's Ring. London: Methuen.

MacDonald, D. and Dawkins, M. 1981. Ethology - the science and the tool. In: Sperlinger, D. ed. Animals in Research. New York: John Wiley and Sons.

Markowitz, H. 1982. Behavioral Enrichment in the Zoo. New York: van Nostrand Reinhold.

Morgan, C.L. 1894. An Introduction to Comparative Psychology. London: Scott.

Pavlov, I.P. 1927. Conditioned Reflexes. (1960 reprint). New York: Dover Books.

Rollin, B.E. 1981. Animal Rights and Human Morality. Buffalo, NY: Prometheus Books.

Singer, P. 1975. Animal Liberation. New York: Avon Books.

Staddon, J.E.R. 1983. Adaptive Behavior and Learning. Cambridge, U.K.: Cambridge University Press.

Tinbergen, N. 1953. The Herring Gull's World. London: Collins.

Tinbergen, N. 1958. Curious Naturalists. London: Country Life.

Uexkull, J. von. 1957. A stroll through the world of animals and men. In: Schiller, C.S. ed. Instinctive Behavior. New York: International Universities Press.

Washburn, M.F. 1917. The Animal Mind. New York: MacMillan.

Watson, J.B. 1924. Psychology from the Standpoint of a Bchaviorist. Philadelphia: Lippincott. 